\title{
Review Article \\ Breast Cancer-Derived Extracellular Vesicles: Characterization and Contribution to the Metastatic Phenotype
}

\author{
Toni M. Green, ${ }^{1}$ Mary L. Alpaugh, ${ }^{2}$ Sanford H. Barsky, \\ Germana Rappa, ${ }^{1}$ and Aurelio Lorico ${ }^{1}$ \\ ${ }^{1}$ Comprehensive Community Cancer Center, Roseman University College of Medicine, Las Vegas, NV 89135, USA \\ ${ }^{2}$ Memorial Sloan Kettering Cancer Center, New York, NY 10065, USA \\ Correspondence should be addressed to Aurelio Lorico; alorico@roseman.edu
}

Received 18 April 2015; Revised 24 September 2015; Accepted 4 October 2015

Academic Editor: Anelli Tiziana

Copyright (C) 2015 Toni M. Green et al. This is an open access article distributed under the Creative Commons Attribution License, which permits unrestricted use, distribution, and reproduction in any medium, provided the original work is properly cited.

\begin{abstract}
The study of extracellular vesicles (EVs) in cancer progression is a complex and rapidly evolving field. Whole categories of cellular interactions in cancer which were originally presumed to be due solely to soluble secreted molecules have now evolved to include membrane-enclosed extracellular vesicles (EVs), which include both exosomes and shed microvesicles (MVs), and can contain many of the same molecules as those secreted in soluble form but many different molecules as well. EVs released by cancer cells can transfer mRNA, miRNA, and proteins to different recipient cells within the tumor microenvironment, in both an autocrine and paracrine manner, causing a significant impact on signaling pathways, mRNA transcription, and protein expression. The transfer of EVs to target cells, in turn, supports cancer growth, immunosuppression, and metastasis formation. This review focuses exclusively on breast cancer EVs with an emphasis on breast cancer-derived exosomes, keeping in mind that breast cancer-derived EVs share some common physical properties with EVs of other cancers.
\end{abstract}

\section{Introduction}

Breast cancer is the most prevalent type of cancer in women [1]. Although a multitude of treatment options are available [2-4], approximately one-third of women worldwide diagnosed with breast cancer still die from the disease, largely from metastasis, especially brain metastasis [5-8]. EVs have been hypothesized to have significant roles in breast cancer growth and metastasis and thus have been evaluated as potential avenues of new therapeutic intervention. EVs, including exosomes and MVs, are secreted in large quantities by cancer cells into the local microenvironment and premetastatic "niche" [9]. While both exosomes and MVs are small (usually $<1 \mu \mathrm{m}$ in diameter), these bilipid membraneenclosed vesicular structures [10-13] have a distinct biogenesis: exosomes are generated through inward budding of an endosome resulting in a multivesicular body (MVB) which is released by subsequent fusion of the MVB with the plasma membrane [14-18], whereas MVs are released directly by budding from the cellular plasma membrane $[15,18,19]$. However, EVs including both MVs and exosomes have been proposed to enter target cells through multiple mechanisms, including ligand-receptor-mediated [20,21], or lipid raftmediated entry $[22,23]$, with EV fusion and uptake greatly influenced by surrounding $\mathrm{pH}$ levels [24]. Exosomes are typically smaller than MVs, being $100 \mathrm{~nm}$ or less in diameter, while the latter are $>100 \mathrm{~nm}$ in size. Some size overlap does exist, however [25-29]. Apoptotic bodies, another type of EV, are poorly characterized and not generally included within the general categories of exosomes or MVs and therefore will not be discussed in this review. This review will discuss breast cancer EV purification, composition, and effect on target cells within the tumor microenvironment to promote cancer growth and metastasis, as well as their possible use as drug delivery vehicles of anticancer therapeutic drugs.

\section{Breast Cancer EV Characterization and Proteomic Profiling}

2.1. Methods of Isolation. There are several variations to the method of isolating MVs and exosomes from cell culture 
supernatants, but most involve differential centrifugation at various speeds to separate particles based on size and density. For EV isolation, cells are grown in media supplemented with exosome-depleted fetal bovine serum (FBS). The first step in purification involves a low-speed centrifugation at $300 \times \mathrm{g}-500 \times \mathrm{g}$ for 5-10 $\mathrm{min}$ to remove live cells [30-32]. The supernatant is then centrifuged at $1200 \times \mathrm{g}-2000 \times \mathrm{g}$ for $10-30 \mathrm{~min}$ to remove dead cells and apoptotic blebs [30, 33-35]. This is followed by centrifugation at $10,000 \times \mathrm{g}$ for $30 \mathrm{~min}$ to remove cellular debris $[30,36]$. To isolate the exosome and MV fractions, the supernatant then undergoes ultracentrifugation at $100,000-200,000 \times \mathrm{g}$ for $60-120 \mathrm{~min}$ $[30,32,36-38]$. The supernatant at this point is discarded and the pellet, containing exosomes and MVs, is washed in phosphate buffered saline (PBS) and ultracentrifuged one final time $[30,36,39,40]$. The PBS is gently decanted and the exosome/MV pellet is resuspended in a small volume of buffer $[35,41]$. If human or mouse serum is used as starting material, an intermediate step using a $0.22 \mu \mathrm{m}$ filter can be employed to supplement the centrifugation steps, resulting in an enrichment in exosomes and small MVs [32, 38, 42]. These methods have been used to isolate MVs and exosomes from both cancer and noncancerous cell lines, including LNCaP prostate cancer, vascular smooth muscle cells (VSMCs), BV2, HCMEC/D3, and several breast cancer cells (MDA-MB231, MCF-7, and MDA-MB-435) [30, 31, 34, 43]. Exosomes purified using this methodology are suitable for liquid chromatography-mass spectrometry (LC-MS) analysis [30, 36]. However, in order to obtain a density-based purer fraction devoid of additional nonspecific proteins and protein aggregates, the exosomal/MV supernatant can be layered on a sucrose gradient prior to high-speed ultracentrifugation $[33,44]$. It is really not possible to separate exosomes from MVs by strictly physical means.

2.2. Size Variation. Scanning electron microscopy (SEM) and transmission electron microscopy (TEM) have been used to determine the physical properties of EVs from many sources, including cancer and noncancerous cell lines, as well as from patients with a myriad of diseases. In general, exosomes are $30-100 \mathrm{~nm}$ in size and have a characteristic round or cupshape, while microvesicles are larger, approximately $100 \mathrm{~nm}-$ $1 \mu \mathrm{m}$, and are composed of a round-shaped, heterogeneous population; however, as previously mentioned, a certain degree of size overlap occurs [11, 35, 40, 42, 44-51]. It is important to note that the cup-shape appearance of exosomes visualized by electron microscopy may be an artifact of the fixation process, and their true shape mirrors that of round microvesicles [17]. In addition, there is also some variation in size of EVs based on the method of visualization. For example, exosomes derived from metastatic MDA-MB-231 breast cancer cells were determined to be $40-120 \mathrm{~nm}$ in size by SEM and contained the typical exosomal marker CD63 [52]. EVs shed from MDA-MB-231 cells, on the other hand, were larger in size and determined to be $57-440 \mathrm{~nm}$ in size with a mean diameter of $121 \pm 54 \mathrm{~nm}$ by TEM [53]. As another example, tissue factor (TF) antigen has also been identified in breast cancer-derived EVs $[53,54] .10 \%$ of MDA-MB-231derived MVs were found to express TF, and although EVs up to $220 \mathrm{~nm}$ contained active TF, most EVs containing active TF were $100 \mathrm{~nm}$ or smaller [53]. In an independent study, TF was instead found in breast cancer MVs 200-350 nm in size. [54]. The term "exosome-like vesicles" (ELV) has been used in some studies to describe vesicles with relatively small size and similar densities, physical characteristics, and protein expression patterns as exosomes [55]. For example, in one study, ELV from MDA-MB-231 cells were $20-180 \mathrm{~nm}$ in size, with the majority being $40-100 \mathrm{~nm}$ in size, and contained particles that were both round and cup-shaped [56]. By TEM, ELVs from MCF-7 and MDA-MB-231 cells were reported by Kruger et al. [57] to be $80-200 \mathrm{~nm}$ in size and round in shape. For the purpose of this review, ELVs will be referred to as exosomes. Nanoparticle tracking analysis (NTA) is another technique frequently used to determine the concentration and size of EVs [35, 37, 58]. For example, Zheng et al. used NTA to examine Rab27-dependent exosome secretion from MDA-MB-231 cells [37]. NTA analysis determined peak exosome size to be $129 \mathrm{~nm}$, while an average of $79 \mathrm{~nm}$ was determined by TEM.

2.3. EV Proteins as Cancer Markers. Cancer cell lines are known to secrete significantly more EVs than noncancerous cell lines [59-63]. In line with this, serum from breast carcinoma $(\mathrm{BrCa})$ patients contained significantly higher levels of exosomes than healthy donors [41, 64, 65]. Several EV proteins are differentially expressed in certain stages and types of breast cancer and may be used as diagnostic markers of cancer progression or as a diagnostic marker, that is, "liquid biopsy" for general cancer diagnosis. For example, the oncogenic cancer marker CD24 [66] was uniquely expressed in serum-derived exosomes from $\mathrm{BrCa}$ patients [65]. In an independent study, FAK and EGFR, which are overexpressed in cancer $[67,68]$, were significantly higher in MVs from BrCa patients compared to healthy donors and were found to be differentially expressed depending on the stage of cancer [41]. Survivin-2B, a splice variant of the native protein, which is an apoptosis inhibitor and associated with decreased survivability [69], has also been identified in EVs from $\mathrm{BrCa}$ patient serum, and the protein expression is lost with the progression of the disease [70]. In addition to CD24, FAK, EGFR, and Survivin, BrCa serum EVs have been found to contain the disintegrin and metalloprotease ADAM10, as well as the tetraspanin CD9 $[41,65,70]$, with the latter being a known functional integrin binding partner in breast cancer cells $[71,72]$ and a molecular marker of EVs. Similarly to EVs from serum, exosomes from BrCa pleural effusions contained ADAM10, CD9, and CD24 but also contained the epithelial cell adhesion molecule (EpCAM) [65], a highly expressed protein on cancer cells [73]. It should be considered, however, that CD9 is present on EVs of both neoplastic and nonneoplastic origin [74]. HSP70 and Annexin-1, the latter of which regulates apoptosis and inflammation [75], were also identified from BrCa pleural effusion-derived exosomes [65]. In addition to BrCa patient samples, several EV proteins have been identified from immortalized cancer cell lines. In one particular study, the tumor marker extracellular matrix metalloproteinase inducer EMMPRIN [76, 77] was identified on SKBR3 and MCF-7 breast cancer-derived MVs, but not 
on exosomes [78]. On the other hand, the tetraspanin CD63, a binding partner of integrins and tumor marker whose expression inversely correlates with cancer metastasis [71, 7984 ], and tumor susceptibility gene 101 (TSG101), which is a subunit of the endosomal sorting complex required for transport-1 (ESCRT-1) [85], were present almost exclusively on exosomes [78]. Others have reported CD63, ALG-2interacting protein $\mathrm{X}$ (Alix), which is involved in exosome biogenesis and endosomal sorting [86, 87], and TSG101, or a combination of these proteins, from MDA-MB-231, MCF7, T47D:A18, and Hs-578T breast cancer-derived exosomes $[37,45,49,50]$. Lysosome-associated membrane glycoprotein 1 (LAMP1) and heat shock cognate 70 (HSC70) were also both found to be in exosomes from MDA-MB-231 cells [56]. Therefore, specific proteins can be used to distinguish breast cancer exosomes from shed MVs.

2.4. Proteomic Profiling. There has been extensive proteomic characterization performed on exosomes from breast cancer cells by liquid chromatography-mass spectrometry (LC-MS). This proteomic characterization demonstrated that exosomal content is diverse in nature and varies depending on the cell line from which they originate. They also contain cytosolic as well as membrane proteins involved in signaling pathways and maintenance of cellular structure. In a study performed by Palazzolo et al., LC-MS identified 32 proteins more abundant in the MDA-MB-231 exosomes compared with the cell lysates [56]. These included cytoskeletal proteins such as cytokeratin 9 (K1C9), tropomyosin 4 (TPM4), and transgelin 2 (TAGL2), proteins regulating cell death, including peroxiredoxin 2 (PRDX2), Annexin A5, and heat shock protein 71 (HSP71), and signal proteins such as integrin $\alpha 6$ and integrin $\alpha 3$ [56]. The latter two proteins are involved in cell migration and therefore play a role in the growth and angiogenesis of tumors [88-93]. Exosomes were also enriched in the beta chain of MHC Class I molecules (B2MG), supporting the involvement of exosomes in altering immune system recognition to promote cancer growth [56]. Consistent with this result, proteomics performed on exosomes from a pleural effusion of a breast cancer patient identified MHC Class I molecules, in addition to B-cell translocation gene 1 (BTG1) and pigment epithelium-derived factor (PEDF) [44]. Since the decrease in tumor surface expression of BTG1 and PEDF has been associated with increased cancer growth and metastasis [94-96], tumor cell exosomal shedding of these proteins obviously decreases the cell surface content of these molecules, which benefits the tumor. Secretome profiling of BT-474 and SKBR3 breast cancer cell lines also showed that exosomes were enriched in proteins associated with antigen processing/presentation, such as heat shock $70 \mathrm{kDa}$ protein 5 (HSPA5), calreticulin (CALR), and proteasome activator complex subunit 2 (PSME2), and proteins associated with glycolysis/gluconeogenesis, such as triosephosphate isomerase 1 (TPI1) and phosphoglycerate mutase 1 (PGAM1) [97]. Proteomics of MCF-7 exosomes showed they contained lipid raft proteins ( $\mathrm{G}$ protein) and raft-associated proteins (profilin II, HSP27) [36], giving insight into the composition of their exosomal membranes. Others have also documented flotillin-1 and cofilin, proteins associated with lipid rafts in MCF-7 exosomes [45]. Villarreal et al. demonstrated exosomes composed a portion of the MCF7 and MDA-MB-231 secretomes, and the former included CD63, along with intracellular proteins such as Annexins $\mathrm{A} 2$ and A4, and a variety of histones and chaperones [98]. Immunoblotting also showed BT-549 breast cancer exosomes contained Annexins A2 and A6 [99]. A separate study showed BT-549 exosomes were taken up through lipid raft domains, which possibly involves Annexin A2 in the target cell, while Annexin A6 may play a role in the movement of exosomes to the late endosomal compartment [22]. Recently, LCMS/MS was used to compare proteins of exosomes from both MDA-MB-231 and MCF-7 cells [57]. MDA-MB-231derived exosomes contained significantly more extracellular matrix proteins than those from MCF-7 cells [57]. MDAMB-231-derived exosomes also contained more proteins with catalytic activity, while MCF-7 exosomes contained more nucleic acid binding and transport proteins [57]. Annexin A1 was exclusive to MCF-7 exosomes while EpCAM was exclusive to MDA-MB-231-derived exosomes and both contained Annexin A2 and $\alpha$-enolase [57], the latter of which has been shown to promote cancer cell growth, migration, and metastasis [100]. MDA-MB-231- and MCF-7-derived exosomes also differentially expressed certain miRNAs. For example, MDA-MB-231-derived exosomes had higher levels of tumorigenic mir-130a and mir-328, while those from MCF7 cells had higher levels of mir-301a [57], the expression of which indicates a negative prognosis of patients with invasive ductal or triple negative breast cancer $[101,102]$. Therefore, exosomes from both breast cancer cell lines contain proteins and miRNA that are oncogenic in nature, yet they each have their own distinctive identifying markers that may relate to the nature and aggressiveness of the cancer type. Both breast cancer-derived exosomes and MVs contain significant, yet distinctive proteins related to breast cancer progression and metastasis (Table 1). Additional breast cancer-derived exosomal proteins have functional roles in immune evasion and miRNA biogenesis and serve as surrogate metastatic markers (Table 2).

\section{Visualization of Breast Cancer EVs}

Direct visualization of breast cancer EV release and uptake in both live and fixed cells by microscopy has been facilitated by fluorescently tagged EV proteins, fluorescent antibodies or peptides, or lipid fluorescent dyes. In particular, several groups have utilized breast cancer cell lines overexpressing the exosomal marker CD63 with a green fluorescent protein (GFP) fusion tag [22, 46, 103]. A striking example is shown by Suetsugu et al., who engineered MDA-MB-231 and mouse mammary tumor (MMT) cells stably expressing CD63-GFP [103]. From these cell lines, the transfer of CD63-GFP exosomes to nonfluorescent autologous breast cancer cells was visualized in vitro and in xenograft models. Upon injection into immunodeficient mice, breast cancer cells expressing CD63-GFP formed tumors that metastasized to the lungs, secreting fluorescent exosomes into both the primary tumor and metastatic microenvironment. Various studies have also utilized PKH dyes, which intercalate with lipids, [32, 52, 104, 
TABLE 1: Comparison of breast cancer-derived MV and exosomal proteins.

\begin{tabular}{lcc}
\hline Role & Microvesicles & Exosomes \\
\hline $\begin{array}{l}\text { Extracellular matrix } \\
\text { degradation }\end{array}$ & EMPRINN & \\
& {$[42,78]$} & ADAM10 [51, 65] \\
& ARF1 [144] & \\
& & Annexins A2, A5, and \\
& RhoA/RhoC & A6 [55, 56, 97, 98] \\
ETCAM $[57,65,120]$ \\
invasion/metastasis & FAK [41] & H2A [46] \\
& EGFR [41] & CD24 [65] \\
& TF [53, 54, 147] & $\alpha$-enolase [57] $[36,65]$ \\
& & Integrins $\alpha 3, \alpha 6[56]$ \\
\hline \multirow{2}{*}{ Cell survival } & IDO [128] & PRDX2 [56] \\
& tTG [107] & HSC70 [56]
\end{tabular}

TABLE 2: Additional breast cancer-derived exosomal proteins and their functional roles.

\begin{tabular}{lc}
\hline Role & Exosomes \\
\hline \multirow{3}{*}{ Immune evasion } & CALR [97] \\
& MHC Class I \\
& molecules \\
& {$[33,37,44,56]$} \\
& PSME2 [97] \\
\hline & Dicer [64] \\
miRNA biogenesis & Ago2 [64] \\
& TRBP [64] \\
\hline & CD63 [45, 49,50, 52, \\
Integrin binding/signaling partner & $64,78,98,139]$ \\
& CD9 [45, 51, 64, 65, \\
& $133,138,139]$ \\
\hline
\end{tabular}

105], or fluorescent antibody or peptide markers [43, 106, 107] to stain MVs and exosomes, demonstrating that breast cancer EVs can transfer nucleic acids and proteins to autologous and heterologous cells within the tumor microenvironment, possibly resulting in the acquisition of the cancer phenotypes, favoring tumor progression, immune evasion, and metastasis.

\section{Horizontal Transmission of miRNA and Proteins}

EVs purified from breast cancer cells typically carry specific mRNAs and miRNAs in addition to proteins and can transfer both transcripts and intact proteins to surrounding cancer cells to promote tumor development. In fact, miRNA is enriched in exosomes derived from the breast cancer cell lines 4T.1, MDA-MB-231, and MCF-7 compared to exosomes from normal breast cells MCF10A and NMuMG [64]. Exosomes from metastatic cell lines (MDA-MB-231 and 4T.1) were also enriched in miRNA compared to exosomes from nonmetastatic cells (MCF-7) [64]. miRNAs were found to be secreted into subpopulations of MVs from MDA-MB-231 cells, with different miRNAs packaged into different types of vesicles [48]. Addition of MVs from MDA-MB-231 cells caused an increase in total RNA in human submandibular gland (HSG) cells [108]. In turn, HSG MVs isolated from HSG cells that were treated with MDA-MB-231-derived MVs contained multiple new mRNAs and an increase in protein levels [108]. Cancer cell-derived exosomes are capable of miRNA processing and biogenesis in addition to transfer of miRNA to target cells [64]. This is evidenced by the detection of proteins involved in miRNA biogenesis, including the RISC loading complex (RLC) proteins Dicer, Ago2, and TRBP, in exosomes from breast cancer cell lines and patient samples but not from normal breast cell lines [64].

\section{Induction of Drug Resistance}

Several mechanisms have been described for breast cancer EV-mediated transfer of drug resistance to promote tumor growth and progression. One such mechanism involves the transfer of P-glyoprotein (P-gp), a protein known to be involved in drug resistance $[109,110]$, through MVs produced from doxorubicin- or docetaxel-resistant breast cancer cells into target endothelial or drug-sensitive cancer cells [111, 112]. These MVs also transferred TrpC5, which caused activation of the NFATc3 transcription factor to stimulate transcription of P-gp mRNA [111]. In addition to the transfer of proteins, the transfer of miRNAs from drugresistant breast cancer-derived exosomes conferred drugresistant properties to target cells [47, 104]. Specifically, exosomes from docetaxel-resistant MCF-7 cells contain miRNAs which downregulate mRNA encoding chemosensitive properties when transferred to nonresistant MCF-7 cells $[47,104]$. Exosomes from doxorubicin-resistant MCF-7 cells also induced chemoresistance in nonresistant MCF-7 cells through transfer of miRNAs [47]. In another study, exosomes produced from tamoxifen-resistant MCF-7 cells were taken up by MCF-7 wild type cells and released miR221/222 [32]. miR-221/222 subsequently caused a decrease in P27 and ERa (targets of miR-221/222) protein levels, which caused an increase in tamoxifen resistance in MCF7 target cells. Besides conferring drug resistance, cancer exosomes can decrease the effectiveness of the therapeutic drug trastuzumab, an antibody that binds HER2 [40]. The presence of HER2 on cancer cells is linked to increased cancer metastasis and tumor proliferation $[113,114]$. Exosomes from SKBR3 and BT-474, both of which are HER2-overexpressing breast cancer cell lines, contain active HER2 and, along with exosomes from HER2-positive breast cancer patient serum, bound to trastuzumab to decrease the drugs' effectiveness at inhibiting SKBR3 cell proliferation [40]. Treatment of BT474 cells with epidermal growth factor (EGF) and heregulin (HRG), which are growth factors secreted by cancer cells [115-117] and activators of HER2 [118, 119], caused a significant increase in exosome production [40], leading to the possibility that enhanced secretion of exosomes may be a way for the tumor microenvironment to support cancer growth in the presence of therapeutic agents. Consistent with these results, $\mathrm{HER}_{2}{ }^{+}$exosomes from BT-474 and SKBR3 cells decreased the trastuzumab-induced cytotoxic effects of peripheral blood mononuclear cells (PBMC) against BT-474 
cells [120]. Besides the transfer of proteins and miRNA to cancer cells, breast cancer EVs can also directly secrete the anticancer drug doxorubicin [121]. The number of secreted MCF-7-derived EVs positively correlated with increasing drug concentration, which suggested EV release is a direct mechanism for imparting chemoresistance within a tumor [121].

\section{Therapeutic Implications of EVs}

It is possible to take advantage of the drug delivery capabilities of exosomes for breast cancer therapy, as shown by Tian et al. [122]. Doxorubicin, incorporated into exosomes from immature dendritic cells (imDC) and taken up by both MDA-MB-231 and MCF-7 cells, caused an inhibition of cell proliferation. When injected into nude mice implanted with MDA-MB-231 tumors, it caused a reduction in tumor growth [122]. Specific targeting to tumors was achieved by incorporating an RGD integrin target sequence in the exosomes which bound to MDA-MB-231 cells, which naturally express high levels of integrin $\alpha \mathrm{v}$ [123]. Exosomes from HEK293 cells stably expressing EGF or EGFR peptide have also been studied as therapeutic agents by targeting breast cancer cells expressing high levels of EGFR (such as the HCC70 breast carcinoma cell line) [39]. The tumor suppressor let-7a miRNA was transfected into HEK293 cells expressing EGFR peptide, and exosomes produced from these cells significantly decreased HCC70 tumor growth in mice [39]. Additionally, treatment of 4T.1 murine breast cancer cells with epigallocatechin gallate (EGCG), a chemical with antitumor effects, caused an increase in the levels of the tumor suppressor miR-16 within exosomes [124]. Exosomes from EGCG-treated breast cancer cells subsequently decreased $\mathrm{NF} \kappa \beta$ activity and M2 polarization in tumorassociated macrophages (TAM) through miR-16 [124]. M2 macrophages, which inhibit inflammation during the end stages of inflammatory processes such as wound healing [125], are known to have tumor-promoting phenotypes [126, 127]. Consequently, therapeutic agents can induce transfer of tumor suppressors to surrounding macrophages through exosomes to decrease their cancer-associated properties.

\section{EVs as Immunomodulators}

Many groups have studied the immunosuppressive effects of tumor-derived EVs and their relation to cancer progression within the tumor microenvironment (Figure 1). In one study, MVs from $36 \%$ of breast cancer patients contained indoleamine 2,3-dioxygenase (IDO), an enzyme that has a role in immunosuppression and tumor survival [128]. Another example of exosomal-mediated immune modulation was described in a study involving TS/A murine mammary tumor-derived exosomes, which were found to act as immune system suppressors to promote tumor progression by inhibiting the differentiation of myeloid precursors in the bone marrow into dendritic cells, partially through induction of IL-6 mRNA [129]. Myeloid-derived suppressor cells (MDSCs) are involved in tumor growth, partially through the inhibition of $\mathrm{T}$-cell activation via Toll-like receptor
(TLR) adaptor protein MyD88 [130]. Murine melanomaderived exosomes were found to exacerbate the effects of MDSCs, which included the induction of the proinflammatory cytokine CCL2 through MyD88 [131]. This same study also discovered that 4T.1-derived exosomes caused an increase in lung metastases through CCL2 [131]. Similarly, breast cancer TS/A-derived exosomes injected into a mouse model caused an increase of MDSCs within both the primary tumor and the spleen [132]. Breast tumor-derived exosomes have also been found to reduce the immune response by inhibiting NK cytotoxicity. In one case, TS/A and 4T.1 breast tumor-derived exosomes inhibited activated NK cell proliferation and prevented them from killing TS/A and 4T.1 tumor cells [133].

In another study, injection of TS/A tumor-derived exosomes into the general circulation of mice decreased the cytotoxicity of $\mathrm{NK}$ cells by reducing the percentage and activity of NK cells [105]. TS/A-, 4T.1-, and MDA-MB231-derived exosomes also decreased stimulated NK cell proliferation, and mice implanted with TS/A or 4T.1 tumors and treated with TS/A or 4T.1 breast tumor-derived exosomes had more rapid tumor growth and metastases compared to controls [105]. The human MHC Class I chain-related genes MICA and MICB are ligands of the NKG2D receptor and stimulate the immune response by activating T-cells [134137]. To evade detection by the immune system, MDA-MB231-derived exosomes lack MICA or MICB and therefore there is no immune stimulation [138]. Furthermore, ADAM17 in MDA-MB-231 breast cancer cells cleaves MICA/MICB from the cell surface of the cancer cell to produce a soluble form, sMICA/sMICB, which may result in a type of immune decoy [138]. Exosomes from T47D breast carcinoma cells decreased the amount of NKG2D-positive lymphocytes within peripheral blood lymphocytes (PBL), which was modulated through NKG2D ligands such as MICB, CD81, and MHC Class I on exosomes [33]. These T47D-derived exosomes also led to inhibition of the cytotoxic function of $\mathrm{CD}^{+}$T-cells, which may be related to the downregulation of NKG2D [33]. This could be yet another mechanism for cancer to evade and/or inhibit the host immune system. A study by Deng et al. showed exosomes isolated from the 4T.1 breast cancer cell line that had interacted with immunosuppressive leukocytes from the tumor microenvironment conferred properties that enhanced tumor metastasis through production of MMP-9 and proinflammatory cytokines [139]. One interesting study suggested how the structural interactions of MDA-MB-231- and MCF-7-derived MVs with human beta-defensin 6 (hBD6), a class of proteins with antimicrobial activity [140], were linked to metastatic potential [141]. There were more nuclear magnetic resonance (NMR) chemical shifts and larger resonance intensity ratios associated with MCF-7-derived MVs compared to MDAMB-231-derived MVs upon association with hBD6, which indicated stronger binding to the MCF-7-derived MVs [141]. This group proposed the weaker interaction of MDA-MB231-derived MVs with hBD6 could suggest a greater capability of evading immune detection and one explanation for the increased metastatic properties of this cell line [141]. 


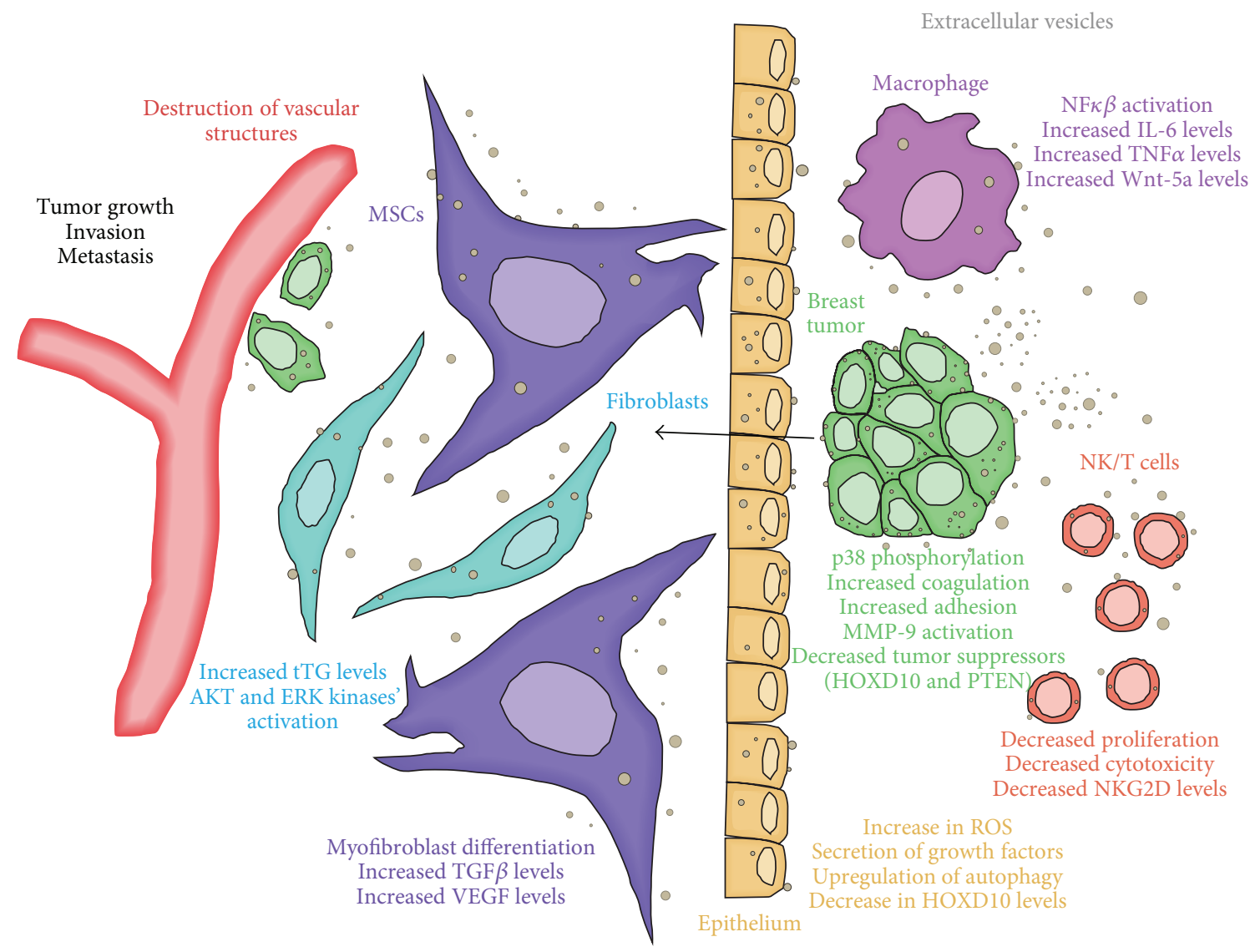

FIGURE 1: Schematic of the numerous interactions between breast tumor-derived EVs and stromal, epithelial, and immune cells within the tumor niche and the resulting changes that enhance cancer growth and metastasis. Breast cancer cells avoid detection from the immune system through EV-mediated decrease in the cytotoxicity of NK and T-cells and secretion of proinflammatory cytokines from macrophages. Tumor EVs enter fibroblasts and stimulate proangiogenic ERK and AKT kinase activation. Concurrently, EVs cause the secretion of oncogenic cytokines TGF $\beta$ and VEGF in mesenchymal stem cells. Additionally, tumor EVs enter surrounding cancer cells to upregulate signaling pathways that promote growth and metastasis, including increases in coagulation, adhesion, and a decrease in levels of tumor suppressors. To promote invasion, EVs induce epithelial cells to secrete growth factors and cause destruction of endothelial vascular structures, thus enhancing tumor growth.

\section{EV Contribution to Breast Tumor Growth and Metastasis}

8.1. EV Transfer of Cancerous Phenotypes. As mentioned above, cancer cell-derived EVs contain a number of oncogenic proteins and miRNAs, which can be transported to surrounding cancer cells to elicit phenotypic changes within target cells. Several groups have investigated the mechanisms through which breast tumor-derived EVs upregulate prometastatic pathways after entering nearby cancer cells. One scenario involves breast cancer MVs increasing cancer cell invasion through extracellular matrix metalloproteinase inducer- (EMPRINN-) dependent phosphorylation of p38 [42]. MDA-MB-231-derived MVs also contain RhoA and RhoC GTPases, which are upregulated in cancer and involved in invasion and metastasis [142, 143], as well as ADPribosylation factor 1 (ARF1), which is associated with MV release and MMP-9 activity within MVs [144]. MMP-9 is involved in the degradation of extracellular matrix, a critical step in cancer cell invasion $[145,146]$. MDA-MB-231-derived
MVs have also been reported to transfer TF to MCF-7 cells to cause increase in procoagulant activity [147], which has been correlated with increased metastatic capabilities [148]. Cellular adhesion is also known to be important in the growth and metastatic progression of cancer cells [149, 150]. To this end, the uptake of exosomes derived from BT-549 cells into target cancer cells caused increased cellular adhesion and spreading through histone $\mathrm{H} 2 \mathrm{~A}$ binding to heparin sulfate proteoglycans [46]. Another study by Melo et al. [64] highlighted the importance of exosomal miRNA processing in tumor growth. This group showed that breast cancer exosomes have all the components required for cell-independent processing of pre-miRNAs into mature miRNAs. By treating normal breast cells with exosomes from metastatic breast cancer cells and measuring miRNA changes within the target cell, they showed that exosomal miRNAs have the ability to alter the transcriptome of target cells. Similarly, treatment of MCF10A cells with MDA-MB-231-derived exosomes led to upregulation of miRNAs involved in cancer metastasis, resulting in downregulation of proteins including PTEN 
and HOXD10, as well as increases in MCF-710A viability, proliferation, and colony formation, all processes in which the capability of miRNA biogenesis was essential. MDAMB-231-derived exosomes injected with MCF10A cells also caused tumor growth in nude mice, which was decreased when miRNA biogenesis within exosomes was inhibited [64]. Therefore, cancer growth is influenced by miRNA biogenesis in exosomes. In addition to miRNA, exosomes can also transfer cancerous properties to heterologous cancer cells to promote tumor aggressiveness and metastasis. O'Brien et al. demonstrated that exosomes isolated from an invasive variant of triple negative breast cancer (TNBC) cells $\left(\operatorname{Hs}_{\left.578 \mathrm{Ts}_{(\mathrm{i}) 8}\right)}\right.$ ) caused an increase in the growth rate, migration, and invasive capacity of SKBR3, MDA-MB-231, and HCC1954 breast cancer cell lines, as well as causing an increase in endothelial cell angiogenesis [50]. Galindo-Hernandez et al. reported that an epithelial-mesenchymal transition-like process was induced in MCF10A cells by EVs isolated from plasma of women with breast carcinoma [151]. Exosomes from the serum of patients with TNBC also produced significantly greater invasion of breast cancer cell lines compared to exosomes from healthy donors [50]. Recently, using a TNBC xenograft model of inflammatory breast cancer (MARY$\mathrm{X})$ [152], a model which forms tight tumor cell aggregates (termed spheroids) in vitro, which represent the in vivo equivalent of lymphovascular tumor emboli, complete exosomal biogenesis could be observed by TEM (Figure 2). In this model, large numbers of secreted exosomes observed within the intercellular space between cancer cells suggest the possibility that important exosomal-mediated autocrine signaling occurs in actual tumor emboli which may give them a survival advantage (unpublished observations). Since most breast cancers are adenocarcinomas, which are present in both metastatic sites and the circulation as circulating tumor cells (CTCs), this exosomal-mediated autocrine signaling may have wide therapeutic implications.

8.2. Hypoxic Effects on EV-Influenced Metastasis. Cancer cells have a unique ability to survive and grow under hypoxic conditions [153]. Exosome secretion plays a role in the ability of tumors to metastasize under limited oxygen conditions. Hypoxic conditions are known to increase MV and exosome release from a variety of breast cancer cell lines, including MCF-7, MDA-MB-231, and SK-BR3 [43, 45], which requires hypoxia-inducible factor- (HIF-) dependent RAB22A expression [43]. Hypoxic breast cancer-derived MVs caused increases in tumor metastasis and invasion, which were dependent on the expression of RAB22A within the MVs [43]. A low $\mathrm{pH}$ often accompanies hypoxia in cancerous phenotypes [154], and it has been previously reported that melanoma-derived exosome secretion and uptake increases with decreased $\mathrm{pH}$ levels [24]. Additional studies showed that the MCF-7 breast cancer cell line became more resistant to the chemotherapeutic drug cisplatin at lower $\mathrm{pH}$ levels [155], and treatment of metastatic breast cancer patients with proton-pump inhibitors (PPI) led to enhanced efficacy of chemotherapy [156]. From these results, it can be proposed that treatment of breast carcinomas with PPIs could lead to decreased exosome number within the

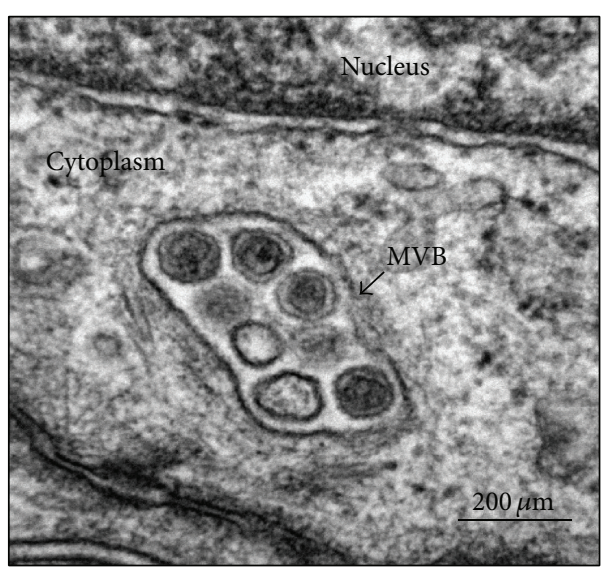

FIGURE 2: Early biogenesis of exosomes present within a multivesicular body (MBV) of the MARY-X spheroids is depicted. The MBV will subsequently fuse with the plasma membrane and exosomes will be released from the cell.

tumor microenvironment, leading to enhanced chemosensitivity. Breast cancer-derived exosomes produced under hypoxic conditions can also promote inflammatory cross talk within the tumor niche to promote growth, which is decreased by activation of nuclear receptors within the cancer cell [157]. This leads to the possibility of nuclear receptors as new therapeutic targets, whose efficacy can be increased by taking advantage of the exosome-mediated delivery system between cancer cells.

8.3. Effects on the Tumor/Metastatic Niche. Breast tumor exosomes have the ability to prime the premetastatic niche, which involves the transfer of proteins and activation of signaling pathways within epithelial cells, stromal cells, macrophages, and fibroblasts that promote tumor progression (Figure 1). Several studies have demonstrated that exosomes from cancer cells have this effect on the surrounding microenvironment. MVs derived from MDA-MB-231 have been shown to confer cancerous phenotypes to NIH 3T3 fibroblasts as well as noncancerous MCF10A human breast epithelial cells, including increased survival and cellular transformation, partly through the transfer of tissue transglutaminase (tTG) [107]. MDA-MB-231-derived MVs caused NIH $3 \mathrm{~T} 3$ tumor growth in nude mice through activation of AKT and ERK kinases in NIH 3T3 fibroblast cells, requiring tTG [107]. In another example, MDA-MB-231-, T47DA18-, and MCF-7-derived exosomes were taken up by human primary mammary epithelial cells (HMEC), causing an increase in reactive oxygen species (ROS) and secretion of tumor growth factors from HMECs [49]. Increases in ROS by breast cancer-derived exosomes led to upregulation of autophagy through an increase in the phosphorylation of DNA damage response proteins (DDR) (ATM, H2AX, and Chk1) and p53 stabilization [49]. Autophagy, which is the internalization of damaged material within a cell, is an important survival mechanism for cancer cells to acquire energy to keep up with the demands of tumor growth [158]. In addition, cancer exosomes caused an increase in HMEC 
autophagy in part by transferring LC3 proteins, involved in autophagosome cargo sorting [159], to HMEC cells [49]. A study done by Cho et al. indicates that breast tumor-derived exosomes can differentiate mesenchymal stem cells (MSC) into tumor-associated myofibroblasts [160], which are known to contribute to tumor growth, progression, and metastasis within the tumor microenvironment [161]. In particular, MDA-MB-231- and MCF-7-derived exosomes increased the expression of $\alpha$-SMA, which is an indicator of myofibroblasts, through the activation of SMAD2-dependent pathways, and cytokines such as TGF $\beta$ and VEGF, which support tumor growth, when added to adipose-derived mesenchymal stem cells (ADSC) [160]. Metastatic enhancement of breast cancer cells is regulated through exosomal miR-105, which can target tight junctions in primary human microvascular endothelial cells (HMVEC), resulting in the increased permeability of cell monolayers, the destruction of vascular structures, and induced HMVEC migration [162]. Additionally, treatment of HMVECs with MDA-MB-231-derived exosomes increased transendothelial migration of MDA-MB-231 cells through HMVEC monolayer, and mice pretreated with MDA-MB231-derived exosomes and then injected with MDA-MB-231 cells had increased lung and brain metastases [162]. MDAMB-231-derived exosomes can also transfer miR-10b, which is more highly expressed in exosomes from metastatic as opposed to nonmetastatic cell lines, to immortalized human mammary epithelial (HMLE) cells to reduce levels of the tumor suppressor HOXD10 [163] protein and subsequently increase cell invasion [52]. Inflammation from macrophages promotes tumor growth and metastasis to distant sites [164, 165]. Concurrently, macrophages treated with breast cancerderived exosomes caused significant increases in NF- $\kappa \beta$ activation and production of inflammatory cytokines (including IL- 6 and TNF $\alpha$ ) compared to exosomes from normal breast cells through exosomal binding to the Toll-like receptor 2 (TLR2) [106]. Additionally, MDA-MB-231 cells transplanted into immunodeficient mice released exosomes that entered distant macrophages in lymph nodes, causing increases in IL-6 expression [106]. This showed breast cancer exosomes can alter macrophage phenotypes to cause an increase in metastasis. In another study, MCF-7-derived EVs transferred Wnt 5a mRNA, which plays an important role in tumor invasion, to macrophages, where it was translated into Wnt 5 a protein [78]. This Wnt 5a protein in macrophages was then packaged into EVs and secreted from cells. The macrophage EVs containing Wnt 5a subsequently caused an increase in MCF-7 cell invasion [78]. Therefore, breast cancer EVs can transfer mRNA to macrophages, which can, in turn, translate and package cancerous proteins into vesicles, which are then subsequently secreted into the tumor microenvironment to enhance the invasive capacity of surrounding cancer cells in a paracrine manner.

\section{Conclusions}

There have been many proteins identified within breast cancer EVs that give insight into the nature and severity of the disease. These could serve as possible diagnostic markers to be used in conjunction with current analytical techniques. Both exosomes and MVs are key players in the progression of cancer and elicit a multitude of cellular responses within their target cells, at both the mRNA and protein levels. There are multiple mechanisms by which cancer cells avoid immune system recognition through EVs, such as secretion of immunosuppressive proteins, inhibition of NK cell proliferation, or a decrease in $\mathrm{CD}^{+} \mathrm{T}$ cell cytotoxicity. Some targeted breast cancer therapies have been investigated employing exosomes as a vehicle for drug delivery, but due to the complex nature of EV-cell interactions, additional studies need to be performed to achieve a therapeutic strategy with a favorable therapeutic index using an exosome approach. Tumors have the unique ability to support their progression by using MVs and exosomes to deliver procancerous transcripts and proteins, to both other cancer cells and nontransformed cells. EVs are key players within the cancer niche and are able to thrive in the acidic, hypoxic environments common to tumors in order to confer prometastatic phenotypes such as inflammation, migration, and invasion. While there have been many advances in recent years, future investigations involving EVs and their contribution to tumor growth are crucial to the continued understanding of cancer development.

\section{Conflict of Interests}

The authors declare that there is no conflict of interests regarding the publication of this paper.

\section{References}

[1] C. E. Desantis, C. C. Lin, A. B. Mariotto et al., "Cancer treatment and survivorship statistics, 2014," CA Cancer Journal for Clinicians, vol. 64, no. 4, pp. 252-271, 2014.

[2] G. Mustacchi, L. Biganzoli, P. Pronzato et al., "HER2-positive metastatic breast cancer: a changing scenario," Critical Reviews in Oncology/Hematology, vol. 95, no. 1, pp. 78-87, 2015.

[3] A. Sonnenblick and M. Piccart, "Adjuvant systemic therapy in breast cancer: quo vadis?" Annals of Oncology, vol. 26, no. 8, pp. 1629-1634, 2015.

[4] S. Tangutoori, P. Baldwin, and S. Sridhar, "PARP inhibitors: a new era of targeted therapy," Maturitas, vol. 81, no. 1, pp. 5-9, 2015.

[5] R. L. Siegel, K. D. Miller, and A. Jemal, "Cancer statistics, 2015," CA Cancer Journal for Clinicians, vol. 65, no. 1, pp. 5-29, 2015.

[6] D. P. Kodack, V. Askoxylakis, G. B. Ferraro, D. Fukumura, and R. K. Jain, "Emerging strategies for treating brain metastases from breast cancer," Cancer Cell, vol. 27, no. 2, pp. 163-175, 2015.

[7] L. Gerratana, V. Fanotto, M. Bonotto et al., "Pattern of metastasis and outcome in patients with breast cancer," Clinical and Experimental Metastasis, vol. 32, pp. 125-133, 2015.

[8] A. J. Redig and S. S. Mcallister, "Breast cancer as a systemic disease: a view of metastasis," Journal of Internal Medicine, vol. 274, no. 2, pp. 113-126, 2013.

[9] T. H. Lee, E. D’Asti, N. Magnus, K. Al-Nedawi, B. Meehan, and J. Rak, "Microvesicles as mediators of intercellular communication in cancer-the emerging science of cellular 'debris," Seminars in Immunopathology, vol. 33, no. 5, pp. 455-467, 2011.

[10] E. van der Pol, A. N. Böing, P. Harrison, A. Sturk, and R. Nieuwland, "Classification, functions, and clinical relevance of 
extracellular vesicles," Pharmacological Reviews, vol. 64, no. 3, pp. 676-705, 2012.

[11] F. Jansen, X. Yang, S. Proebsting et al., "MicroRNA expression in circulating microvesicles predicts cardiovascular events in patients with coronary artery disease," Journal of the American Heart Association, vol. 3, no. 6, Article ID e001249, 2014.

[12] F. Pucci and M. J. Pittet, "Molecular pathways: tumor-derived microvesicles and their interactions with immune cells in vivo," Clinical Cancer Research, vol. 19, no. 10, pp. 2598-2604, 2013.

[13] G. Camussi, M. C. Deregibus, S. Bruno, V. Cantaluppi, and L. Biancone, "Exosomes/microvesicles as a mechanism of cell-tocell communication," Kidney International, vol. 78, no. 9, pp. 838-848, 2010.

[14] K. Denzer, M. J. Kleijmeer, H. F. G. Heijnen, W. Stoorvogel, and H. J. Geuze, "Exosome: from internal vesicle of the multivesicular body to intercellular signaling device," Journal of Cell Science, vol. 113, no. 19, pp. 3365-3374, 2000.

[15] J. H. Hurley and G. Odorizzi, "Get on the exosome bus with ALIX," Nature Cell Biology, vol. 14, no. 7, pp. 654-655, 2012.

[16] L. Urbanelli, A. Magini, S. Buratta et al., "Signaling pathways in exosomes biogenesis, secretion and fate," Genes, vol. 4, no. 2, pp. 152-170, 2013.

[17] G. Raposo and W. Stoorvogel, "Extracellular vesicles: exosomes, microvesicles, and friends," The Journal of Cell Biology, vol. 200, no. 4, pp. 373-383, 2013.

[18] H. F. G. Heijnen, A. E. Schiel, R. Fijnheer, H. J. Geuze, and J. J. Sixma, "Activated platelets release two types of membrane vesicles: microvesicles by surface shedding and exosomes derived from exocytosis of multivesicular bodies and $\alpha$-granules," Blood, vol. 94, no. 11, pp. 3791-3799, 1999.

[19] V. Muralidharan-Chari, J. W. Clancy, A. Sedgwick, and C. D'Souza-Schorey, "Microvesicles: mediators of extracellular communication during cancer progression," Journal of Cell Science, vol. 123, no. 10, pp. 1603-1611, 2010.

[20] A. E. Morelli, A. T. Larregina, W. J. Shufesky et al., "Endocytosis, intracellular sorting, and processing of exosomes by dendritic cells," Blood, vol. 104, no. 10, pp. 3257-3266, 2004.

[21] I. Del Conde, C. N. Shrimpton, P. Thiagarajan, and J. A. López, "Tissue-factor-bearing microvesicles arise from lipid rafts and fuse with activated platelets to initiate coagulation," Blood, vol. 106, no. 5, pp. 1604-1611, 2005.

[22] R. B. Koumangoye, A. M. Sakwe, J. S. Goodwin, T. Patel, and J. Ochieng, "Detachment of breast tumor cells induces rapid secretion of exosomes which subsequently mediate cellular adhesion and spreading," PLoS ONE, vol. 6, no. 9, Article ID e24234, 2011.

[23] A. Elmi, E. Watson, P. Sandu et al., "Campylobacter jejuni outer membrane vesicles play an important role in bacterial interactions with human intestinal epithelial cells," Infection and Immunity, vol. 80, no. 12, pp. 4089-4098, 2012.

[24] I. Parolini, C. Federici, C. Raggi et al., "Microenvironmental pH is a key factor for exosome traffic in tumor cells," The Journal of Biological Chemistry, vol. 284, no. 49, pp. 34211-34222, 2009.

[25] X. Loyer, A.-C. Vion, A. Tedgui, and C. M. Boulanger, "Microvesicles as cell-cell messengers in cardiovascular diseases," Circulation Research, vol. 114, no. 2, pp. 345-353, 2014.

[26] F. F. Van Doormaal, A. Kleinjan, M. Di Nisio, H. R. Büller, and R. Nieuwland, "Cell-derived microvesicles and cancer," Netherlands Journal of Medicine, vol. 67, no. 7, pp. 266-273, 2009.

[27] A. Vargas, S. Zhou, M. Éthier-Chiasson et al., "Syncytin proteins incorporated in placenta exosomes are important for cell uptake and show variation in abundance in serum exosomes from patients with preeclampsia," The FASEB Journal, vol. 28, no. 8, pp. 3703-3719, 2014.

[28] C. Thery, S. Amigorena, G. Raposo, and A. Clayton, "Isolation and characterization of exosomes from cell culture supernatants and biological fluids," Current Protocols in Cell Biology, chapter 3: unit 3.22, 2006.

[29] A. Al Faraj, F. Gazeau, C. Wilhelm et al., "Endothelial cellderived microparticles loaded with iron oxide nanoparticles: feasibility of MR imaging monitoring in mice," Radiology, vol. 263, no. 1, pp. 169-178, 2012.

[30] A. S. Haqqani, C. E. Delaney, T.-L. Tremblay, C. Sodja, J. K. Sandhu, and D. B. Stanimirovic, "Method for isolation and molecular characterization of extracellular microvesicles released from brain endothelial cells," Fluids and Barriers of the CNS, vol. 10, no. 1, article 4, 2013.

[31] L. Comelli, S. Rocchiccioli, S. Smirni et al., "Characterization of secreted vesicles from vascular smooth muscle cells," Molecular BioSystems, vol. 10, no. 5, pp. 1146-1152, 2014.

[32] Y. Wei, X. Lai, S. Yu et al., "Exosomal miR-221/222 enhances tamoxifen resistance in recipient ER-positive breast cancer cells," Breast Cancer Research and Treatment, vol. 147, pp. 423431, 2014.

[33] A. Clayton and Z. Tabi, "Exosomes and the MICA-NKG2D system in cancer," Blood Cells, Molecules, and Diseases, vol. 34, no. 3, pp. 206-213, 2005.

[34] R. Crescitelli, C. Lässer, T. G. Szabó et al., "Distinct RNA profiles in subpopulations of extracellular vesicles: apoptotic bodies, microvesicles and exosomes," Journal of Extracellular Vesicles, vol. 2, Article ID 20677, 2013.

[35] E. Lázaro-Ibáñez, A. Sanz-Garcia, T. Visakorpi et al., "Different gDNA content in the subpopulations of prostate cancer extracellular vesicles: apoptotic bodies, microvesicles, and exosomes," Prostate, vol. 74, no. 14, pp. 1379-1390, 2014.

[36] S. Staubach, H. Razawi, and F.-G. Hanisch, "Proteomics of MUC1-containing lipid rafts from plasma membranes and exosomes of human breast carcinoma cells MCF-7," Proteomics, vol. 9, no. 10, pp. 2820-2835, 2009.

[37] Y. Zheng, E. C. Campbell, J. Lucocq, A. Riches, and S. J. Powis, "Monitoring the Rab27 associated exosome pathway using nanoparticle tracking analysis," Experimental Cell Research, vol. 319, no. 12, pp. 1706-1713, 2013.

[38] G. Rappa, J. Mercapide, F. Anzanello, R. M. Pope, and A. Lorico, "Biochemical and biological characterization of exosomes containing prominin-1/CD133," Molecular Cancer, vol. 12, article 62, 2013.

[39] S.-I. Ohno, M. Takanashi, K. Sudo et al., "Systemically injected exosomes targeted to EGFR deliver antitumor microrna to breast cancer cells," Molecular Therapy, vol. 21, no. 1, pp. 185191, 2013.

[40] V. Ciravolo, V. Huber, G. C. Ghedini et al., "Potential role of HER2-overexpressing exosomes in countering trastuzumabbased therapy," Journal of Cellular Physiology, vol. 227, no. 2, pp. 658-667, 2012.

[41] O. Galindo-Hernandez, S. Villegas-Comonfort, F. Candanedo et al., "Elevated concentration of microvesicles isolated from peripheral blood in breast cancer patients," Archives of Medical Research, vol. 44, no. 3, pp. 208-214, 2013.

[42] K. Menck, C. Scharf, A. Bleckmann et al., "Tumor-derived microvesicles mediate human breast cancer invasion through differentially glycosylated EMMPRIN," Journal of Molecular Cell Biology, vol. 7, no. 2, pp. 143-153, 2015. 
[43] T. Wang, D. M. Gilkes, N. Takano et al., "Hypoxia-inducible factors and RAB22A mediate formation of microvesicles that stimulate breast cancer invasion and metastasis," Proceedings of the National Academy of Sciences of the United States of America, vol. 111, no. 31, pp. E3234-E3242, 2014.

[44] M. P. Bard, J. P. Hegmans, A. Hemmes et al., "Proteomic analysis of exosomes isolated from human malignant pleural effusions," American Journal of Respiratory Cell and Molecular Biology, vol. 31, no. 1, pp. 114-121, 2004.

[45] H. W. King, M. Z. Michael, and J. M. Gleadle, "Hypoxic enhancement of exosome release by breast cancer cells," $B M C$ Cancer, vol. 12, article 421, 2012.

[46] G. Nangami, R. Koumangoye, J. S. Goodwin et al., "FetuinA associates with histones intracellularly and shuttles them to exosomes to promote focal adhesion assembly resulting in rapid adhesion and spreading in breast carcinoma cells," Experimental Cell Research, vol. 328, no. 2, pp. 388-400, 2014.

[47] W.-X. Chen, X.-M. Liu, M.-M. Lv et al., "Exosomes from drug-resistant breast cancer cells transmit chemoresistance by a horizontal transfer of micrornas," PLoS ONE, vol. 9, no. 4, Article ID e95240, 2014.

[48] J. Palma, S. C. Yaddanapudi, L. Pigati et al., "MicroRNAs are exported from malignant cells in customized particles," Nucleic Acids Research, vol. 40, no. 18, pp. 9125-9138, 2012.

[49] S. Dutta, C. Warshall, C. Bandyopadhyay, D. Dutta, and B. Chandran, "Interactions between exosomes from breast cancer cells and primary mammary epithelial cells leads to generation of reactive oxygen species which induce DNA damage response, stabilization of p53 and autophagy in epithelial cells," PLOS ONE, vol. 9, no. 5, Article ID e97580, 2014.

[50] K. O’Brien, S. Rani, C. Corcoran et al., "Exosomes from triple-negative breast cancer cells can transfer phenotypic traits representing their cells of origin to secondary cells," European Journal of Cancer, vol. 49, no. 8, pp. 1845-1859, 2013.

[51] J. N. Higginbotham, M. Demory Beckler, J. D. Gephart et al., "Amphiregulin exosomes increase cancer cell invasion," Current Biology, vol. 21, no. 9, pp. 779-786, 2011.

[52] R. Singh, R. Pochampally, K. Watabe, Z. Lu, and Y. Mo, "Exosome-mediated transfer of miR-10b promotes cell invasion in breast cancer," Molecular Cancer, vol. 13, article 256, 2014.

[53] D. Gheldof, J. Hardij, F. Cecchet, B. Chatelain, J. Dogné, and F. Mullier, "Thrombin generation assay and transmission electron microscopy: a useful combination to study tissue factor-bearing microvesicles," Journal of Extracellular Vesicles, vol. 2, 2013.

[54] C. Ettelaie, M. E. Collier, A. Maraveyas, and R. Ettelaie, "Characterization of physical properties of tissue factor-containing microvesicles and a comparison of ultracentrifuge-based recovery procedures," Journal of Extracellular Vesicles, vol. 3, Article ID 23592, 2014.

[55] M. Kesimer, M. Scull, B. Brighton et al., "Characterization of exosome-like vesicles released from human tracheobronchial ciliated epithelium: a possible role in innate defense," The FASEB Journal, vol. 23, no. 6, pp. 1858-1868, 2009.

[56] G. Palazzolo, N. N. Albanese, G. Di Cara, D. Gygax, M. L. Vittorelli, and I. Pucci-Minafra, "Proteomic analysis of exosome-like vesicles derived from breast cancer cells," Anticancer Research, vol. 32, no. 3, pp. 847-860, 2012.

[57] S. Kruger, Z. Y. A. Elmageed, D. H. Hawke et al., "Molecular characterization of exosome-like vesicles from breast cancer cells," BMC Cancer, vol. 14, no. 1, article 44, 2014.

[58] P. Jenjaroenpun, Y. Kremenska, V. M. Nair, M. Kremenskoy, B. Joseph, and I. V. Kurochkin, "Characterization of RNA in exosomes secreted by human breast cancer cell lines using nextgeneration sequencing," PeerJ, vol. 2013, no. 1, article e201, 2013.

[59] J. Silva, V. Garcia, M. Rodriguez et al., "Analysis of exosome release and its prognostic value in human colorectal cancer," Genes, Chromosomes and Cancer, vol. 51, no. 4, pp. 409-418, 2012.

[60] M. Logozzi, A. De Milito, L. Lugini et al., "High levels of exosomes expressing CD63 and caveolin-1 in plasma of melanoma patients," PLoS ONE, vol. 4, no. 4, Article ID e5219, 2009.

[61] D. D. Taylor and C. Gercel-Taylor, "MicroRNA signatures of tumor-derived exosomes as diagnostic biomarkers of ovarian cancer," Gynecologic Oncology, vol. 110, no. 1, pp. 13-21, 2008.

[62] M. J. Szczepanski, M. Szajnik, A. Welsh, T. L. Whiteside, and M. Boyiadzis, "Blast-derived microvesicles in sera from patients with acute myeloid leukemia suppress natural killer cell function via membrane-associated transforming growth factorß1," Haematologica, vol. 96, no. 9, pp. 1302-1309, 2011.

[63] E. U. Wieckowski, C. Visus, M. Szajnik, M. J. Szczepanski, W. J. Storkus, and T. L. Whiteside, "Tumor-derived microvesicles promote regulatory $\mathrm{T}$ cell expansion and induce apoptosis in tumor-reactive activated $\mathrm{CD}^{+} \mathrm{T}$ lymphocytes," Journal of Immunology, vol. 183, no. 6, pp. 3720-3730, 2009.

[64] S. A. Melo, H. Sugimoto, J. T. O’Connell et al., "Cancer exosomes perform cell-independent microRNA biogenesis and promote tumorigenesis," Cancer Cell, vol. 26, no. 5, pp. 707-721, 2014.

[65] A.-K. Rupp, C. Rupp, S. Keller et al., "Loss of EpCAM expression in breast cancer derived serum exosomes: role of proteolytic cleavage," Gynecologic Oncology, vol. 122, no. 2, pp. 437-446, 2011.

[66] X. Fang, P. Zheng, J. Tang, and Y. Liu, "CD24: from A to Z," Cellular and Molecular Immunology, vol. 7, no. 2, pp. 100-103, 2010.

[67] V. M. Golubovskaya, F. A. Kwen, and W. G. Cance, "Focal adhesion kinase and cancer," Histology and Histopathology, vol. 24, no. 4, pp. 503-510, 2009.

[68] N. Normanno, A. De Luca, C. Bianco et al., "Epidermal growth factor receptor (EGFR) signaling in cancer," Gene, vol. 366, no. 1, pp. 2-16, 2006.

[69] S. Fukuda and L. M. Pelus, "Survivin, a cancer target with an emerging role in normal adult tissues," Molecular Cancer Therapeutics, vol. 5, no. 5, pp. 1087-1098, 2006.

[70] S. Khan, H. F. Bennit, D. Turay et al., "Early diagnostic value of survivin and its alternative splice variants in breast cancer," BMC Cancer, vol. 14, no. 1, article 176, 2014.

[71] X. Yang, O. V. Kovalenko, W. Tang, C. Claas, C. S. Stipp, and M. E. Hemler, "Palmitoylation supports assembly and function of integrin-tetraspanin complexes," Journal of Cell Biology, vol. 167, no. 6, pp. 1231-1240, 2004.

[72] E. Gustafson-Wagner and C. S. Stipp, "The CD9/CD81 tetraspanin complex and tetraspanin CD151 regulate alpha3betal integrin-dependent tumor cell behaviors by overlapping but distinct mechanisms," PLOS ONE, vol. 8, no. 4, Article ID e61834, 2013.

[73] M. Munz, P. A. Baeuerle, and O. Gires, "The emerging role of EpCAM in cancer and stem cell signaling," Cancer Research, vol. 69, no. 14, pp. 5627-5629, 2009.

[74] S. Mathivanan and R. J. Simpson, "ExoCarta: a compendium of exosomal proteins and RNA," Proteomics, vol. 9, no. 21, pp. 4997-5000, 2009.

[75] L. H. K. Lim and S. Pervaiz, "Annexin 1: the new face of an old molecule," The FASEB Journal, vol. 21, no. 4, pp. 968-975, 2007. 
[76] Y. Tang, P. Kesavan, M. T. Nakada, and L. Yan, "Tumorstroma interaction: positive feedback regulation of extracellular matrix metalloproteinase inducer (EMMPRIN) expression and matrix metalloproteinase-dependent generation of soluble EMMPRIN," Molecular Cancer Research, vol. 2, no. 2, pp. 73-80, 2004.

[77] C. Biswas and M. A. Nugent, "Membrane association of collagenase stimulatory factor(s) from B-16 melanoma cells," Journal of cellular biochemistry, vol. 35, no. 3, pp. 247-258, 1987.

[78] K. Menck, F. Klemm, J. C. Gross, T. Pukrop, D. Wenzel, and C. Binder, "Induction and transport of Wnt 5a during macrophage-induced malignant invasion is mediated by two types of extracellular vesicles," Oncotarget, vol. 4, no. 11, pp. 2057-2066, 2013.

[79] K. J. Radford, R. F. Thorne, and P. Hersey, "Regulation of tumor cell motility and migration by CD63 in a human melanoma cell line," The Journal of Immunology, vol. 158, no. 7, pp. 3353-3358, 1997.

[80] F. Berditchevski, G. Bazzoni, and M. E. Hemler, "Specific association of CD63 with the VLA-3 and VLA- 6 integrins," The Journal of Biological Chemistry, vol. 270, no. 30, pp. 1778417790, 1995.

[81] M. S. Kwon, S.-H. Shin, S.-H. Yim et al., "CD63 as a biomarker for predicting the clinical outcomes in adenocarcinoma of lung," Lung Cancer, vol. 57, no. 1, pp. 46-53, 2007.

[82] M. S. Pols and J. Klumperman, "Trafficking and function of the tetraspanin CD63," Experimental Cell Research, vol. 315, no. 9, pp. 1584-1592, 2009.

[83] K.-K. Jung, X.-W. Liu, R. Chirco, R. Fridman, and H.-R. C. Kim, "Identification of CD63 as a tissue inhibitor of metalloproteinase-1 interacting cell surface protein," The EMBO Journal, vol. 25, no. 17, pp. 3934-3942, 2006.

[84] R. Chirco, X.-W. Liu, K.-K. Jung, and H.-R. C. Kim, "Novel functions of TIMPs in cell signaling," Cancer and Metastasis Reviews, vol. 25, no. 1, pp. 99-113, 2006.

[85] G. Odorizzi, “The multiple personalities of Alix," Journal of Cell Science, vol. 119, no. 15, pp. 3025-3032, 2006.

[86] M. F. Baietti, Z. Zhang, E. Mortier et al., "Syndecan-synteninALIX regulates the biogenesis of exosomes," Nature Cell Biology, vol. 14, no. 7, pp. 677-685, 2012.

[87] C. Bissig and J. Gruenberg, "ALIX and the multivesicular endosome: ALIX in Wonderland," Trends in Cell Biology, vol. 24, no. 1, pp. 19-25, 2014.

[88] H. Larjava, T. Salo, K. Haapasalmi, R. H. Kramer, and J. Heino, "Expression of integrins and basement membrane components by wound keratinocytes," The Journal of Clinical Investigation, vol. 92, no. 3, pp. 1425-1435, 1993.

[89] A. Melchiori, R. Mortarini, S. Carlone et al., "The $\alpha 3 \beta 1$ integrin is involved in melanoma cell migration and invasion," Experimental Cell Research, vol. 219, no. 1, pp. 233-242, 1995.

[90] C. Bouvard, Z. Segaoula, A. De Arcangelis et al., "Tie2dependent deletion of $\alpha 6$ integrin subunit in mice reduces tumor growth and angiogenesis," International Journal of Oncology, vol. 45, no. 5, pp. 2058-2064, 2014.

[91] R. Mukhopadhyay, R. L. Theriault, and J. E. Price, "Increased levels of $\alpha 6$ integrins are associated with the metastatic phenotype of human breast cancer cells," Clinical and Experimental Metastasis, vol. 17, no. 4, pp. 325-332, 1999.

[92] M. Morini, M. Mottolese, N. Ferrari et al., "The $\alpha 3 \beta 1$ integrin is associated with mammary carcinoma cell metastasis, invasion, and gelatinase B (MMP-9) activity," International Journal of Cancer, vol. 87, no. 3, pp. 336-342, 2000.
[93] K. Mitchell, K. B. Svenson, W. M. Longmate et al., "uppression of integrin alpha3betal in breast cancer cells reduces cyclooxygenase-2 gene expression and inhibits tumorigenesis, invasion, and cross-talk to endothelial cells," Cancer Research, vol. 70, no. 15, pp. 6359-6367, 2010.

[94] S. P. Becerra and V. Notario, "The effects of PEDF on cancer biology: mechanisms of action and therapeutic potential," Nature Reviews Cancer, vol. 13, no. 4, pp. 258-271, 2013.

[95] G. G. Sun, Y. F. Lu, Y. J. Cheng, and W. N. Hu, “The expression of BTG1 is downregulated in NSCLC and possibly associated with tumor metastasis," Tumor Biology, vol. 35, no. 4, pp. 2949-2957, 2014.

[96] J. Cai, C. Parr, G. Watkins, W. G. Jiang, and M. Boulton, "Decreased pigment epithelium-derived factor expression in human breast cancer progression," Clinical Cancer Research, vol. 12, no. 11, pp. 3510-3517, 2006.

[97] D. J. Klinke, Y. M. Kulkarni, Y. Wu, and C. Byrne-Hoffman, "Inferring alterations in cell-to-cell communication in HER2+ breast cancer using secretome profiling of three cell models," Biotechnology and Bioengineering, vol. 111, no. 9, pp. 1853-1863, 2014.

[98] L. Villarreal, O. Méndez, C. Salvans, J. Gregori, J. Baselga, and J. Villanueva, "Unconventional secretion is a major contributor of cancer cell line secretomes," Molecular and Cellular Proteomics, vol. 12, no. 5, pp. 1046-1060, 2013.

[99] A. M. Sakwe, R. Koumangoye, B. Guillory, and J. Ochieng, "Annexin A6 contributes to the invasiveness of breast carcinoma cells by influencing the organization and localization of functional focal adhesions," Experimental Cell Research, vol. 317, no. 6, pp. 823-837, 2011.

[100] Y. Song, Q. Luo, H. Long et al., "Alpha-enolase as a potential cancer prognostic marker promotes cell growth, migration, and invasion in glioma," Molecular Cancer, vol. 13, article 65, 2014.

[101] W. Shi, K. Gerster, N. M. Alajez et al., "MicroRNA-301 mediates proliferation and invasion in human breast cancer," Cancer Research, vol. 71, no. 8, pp. 2926-2937, 2011.

[102] H. Yu, H. Li, H. Qian et al., "Upregulation of miR-301a correlates with poor prognosis in triple-negative breast cancer," Medical Oncology, vol. 31, article 283, 2014.

[103] A. Suetsugu, K. Honma, S. Saji, H. Moriwaki, T. Ochiya, and R. M. Hoffman, "Imaging exosome transfer from breast cancer cells to stroma at metastatic sites in orthotopic nude-mouse models," Advanced Drug Delivery Reviews, vol. 65, no. 3, pp. 383-390, 2013.

[104] W.-X. Chen, Y.-Q. Cai, M.-M. Lv et al., "Exosomes from docetaxel-resistant breast cancer cells alter chemosensitivity by delivering microRNAs," Tumour Biology, vol. 35, no. 10, pp. 9649-9659, 2014.

[105] C. Liu, S. Yu, K. Zinn et al., "Murine mammary carcinoma exosomes promote tumor growth by suppression of NK cell function," The Journal of Immunology, vol. 176, no. 3, pp. 13751385, 2006.

[106] A. Chow, W. Zhou, L. Liu et al., "Macrophage immunomodulation by breast cancer-derived exosomes requires Toll-like receptor 2-mediated activation of NF-kappaB," Scientific Reports, vol. 4, article 5750, 2014.

[107] M. A. Antonyak, B. Li, L. K. Boroughs et al., "Cancer cellderived microvesicles induce transformation by transferring tissue transglutaminase and fibronectin to recipient cells," Proceedings of the National Academy of Sciences of the United States of America, vol. 108, no. 12, pp. 4852-4857, 2011. 
[108] C. S. Lau and D. T. W. Wong, "Breast cancer exosome-like microvesicles and salivary gland cells interplay alters salivary gland cell-derived exosome-like microvesicles in vitro," PLoS ONE, vol. 7, no. 3, Article ID e33037, 2012.

[109] W. T. Bellamy, "P-glycoproteins and multidrug resistance," Annual Review of Pharmacology and Toxicology, vol. 36, pp. 161183, 1996.

[110] T. Yamagishi, S. Sahni, D. M. Sharp, A. Arvind, P. J. Jansson, and D. R. Richardson, "P-glycoprotein mediates drug resistance via a novel mechanism involving lysosomal sequestration," The Journal of Biological Chemistry, vol. 288, no. 44, pp. 31761-31771, 2013.

[111] Y. Dong, Q. Pan, L. Jiang et al., "Tumor endothelial expression of P-glycoprotein upon microvesicular transfer of TrpC5 derived from adriamycin-resistant breast cancer cells," Biochemical and Biophysical Research Communications, vol. 446, no. 1, pp. 85-90, 2014.

[112] M.-M. Lv, X.-Y. Zhu, W.-X. Chen et al., "Exosomes mediate drug resistance transfer in MCF-7 breast cancer cells and a probable mechanism is delivery of P-glycoprotein," Tumor Biology, vol. 35, pp. 10773-10779, 2014.

[113] Y. M. Li, Y. Pan, Y. Wei et al., "Upregulation of CXCR4 is essential for HER2-mediated tumor metastasis," Cancer Cell, vol. 6, no. 5, pp. 459-469, 2004.

[114] W. Dean-Colomb and F. J. Esteva, "Her2-positive breast cancer: herceptin and beyond," European Journal of Cancer, vol. 44, no. 18 , pp. 2806-2812, 2008.

[115] S. Huang, J. M. Trujillo, and S. Chakrabarty, "Proliferation of human colon cancer cells: role of epidermal growth factor and transforming growth factor $\alpha$," International Journal of Cancer, vol. 52, no. 6, pp. 978-986, 1992.

[116] P. J. Russell, S. Bennett, and P. Stricker, "Growth factor involvement in progression of prostate cancer," Clinical Chemistry, vol. 44, no. 4, pp. 705-723, 1998.

[117] C. Stove, T. Boterberg, V. Van Marck, M. Mareel, and M. Bracke, "Bowes melanoma cells secrete heregulin, which can promote aggregation and counteract invasion of human mammary cancer cells," International Journal of Cancer, vol. 114, no. 4, pp. 572-578, 2005.

[118] J. L. Macdonald-Obermann, D. Piwnica-Worms, and L. J. Pike, "Mechanics of EGF receptor/ErbB2 kinase activation revealed by luciferase fragment complementation imaging," Proceedings of the National Academy of Sciences of the United States of America, vol. 109, no. 1, pp. 137-142, 2012.

[119] W. E. Holmes, M. X. Sliwkowski, R. W. Akita et al., "Identification of heregulin, a specific activator of p185erbB2," Science, vol. 256, no. 5060, pp. 1205-1210, 1992.

[120] C. Battke, R. Ruiss, U. Welsch et al., "Tumour exosomes inhibit binding of tumour-reactive antibodies to tumour cells and reduce ADCC," Cancer Immunology, Immunotherapy, vol. 60, no. 5, pp. 639-648, 2011.

[121] K. Shedden, X. T. Xie, P. Chandaroy, Y. T. Chang, and G. R. Rosania, "Expulsion of small molecules in vesicles shed by cancer cells: association with gene expression and chemosensitivity profiles," Cancer Research, vol. 63, no. 15, pp. 4331-4337, 2003.

[122] Y. Tian, S. Li, J. Song et al., "A doxorubicin delivery platform using engineered natural membrane vesicle exosomes for targeted tumor therapy," Biomaterials, vol. 35, no. 7, pp. 2383-2390, 2014.

[123] N. C. Wong, B. M. Mueller, C. F. Barbas et al., "Alphav integrins mediate adhesion and migration of breast carcinoma cell lines," Clinical and Experimental Metastasis, vol. 16, pp. 50-61, 1998.
[124] J.-Y. Jang, J.-K. Lee, Y.-K. Jeon, and C.-W. Kim, "Exosome derived from epigallocatechin gallate treated breast cancer cells suppresses tumor growth by inhibiting tumor-associated macrophage infiltration and M2 polarization," BMC Cancer, vol. 13, article 421, 2013.

[125] A. Dey, J. Allen, and P. A. Hankey-Giblin, "Ontogeny and polarization of macrophages in inflammation: blood monocytes versus tissue macrophages," Frontiers in Immunology, vol. 5, article 683, 2014.

[126] A. Sica, T. Schioppa, A. Mantovani, and P. Allavena, “Tumourassociated macrophages are a distinct M2 polarised population promoting tumour progression: potential targets of anti-cancer therapy," European Journal of Cancer, vol. 42, no. 6, pp. 717-727, 2006.

[127] C.-Y. Liu, J.-Y. Xu, X.-Y. Shi et al., "M2-polarized tumorassociated macrophages promoted epithelial-mesenchymal transition in pancreatic cancer cells, partially through TLR4/IL10 signaling pathway," Laboratory Investigation, vol. 93, no. 7, pp. 844-854, 2013.

[128] M. T. Isla Larrain, M. E. Rabassa, E. Lacunza et al., "IDO is highly expressed in breast cancer and breast cancer-derived circulating microvesicles and associated to aggressive types of tumors by in silico analysis," Tumor Biology, vol. 35, no. 7, pp. 6511-6519, 2014.

[129] S. Yu, C. Liu, K. Su et al., "Tumor exosomes inhibit differentiation of bone marrow dendritic cells," Journal of Immunology, vol. 178, no. 11, pp. 6867-6875, 2007.

[130] E.-H. Hong, S.-Y. Chang, B.-R. Lee et al., "Blockade of Myd88 signaling induces antitumor effects by skewing the immunosuppressive function of myeloid-derived suppressor cells," International Journal of Cancer, vol. 132, no. 12, pp. 2839-2848, 2013.

[131] Y. Liu, X. Xiang, X. Zhuang et al., "Contribution of MyD88 to the tumor exosome-mediated induction of myeloid derived suppressor cells," American Journal of Pathology, vol. 176, no. 5, pp. 2490-2499, 2010.

[132] X. Xiang, A. Poliakov, C. Liu et al., "Induction of myeloidderived suppressor cells by tumor exosomes," International Journal of Cancer, vol. 124, no. 11, pp. 2621-2633, 2009.

[133] H.-G. Zhang, H. Kim, C. Liu et al., "Curcumin reverses breast tumor exosomes mediated immune suppression of NK cell tumor cytotoxicity," Biochimica et Biophysica Acta: Molecular Cell Research, vol. 1773, no. 7, pp. 1116-1123, 2007.

[134] H. Das, V. Groh, C. Kuijl et al., "MICA engagement by human Vgamma2Vdelta2 $\mathrm{T}$ cells enhances their antigen-dependent effector function," Immunity, vol. 15, no. 1, pp. 83-93, 2001.

[135] A. Steinle, P. Li, D. L. Morris et al., "Interactions of human NKG2D with its ligands MICA, MICB, and homologs of the mouse RAE-1 protein family," Immunogenetics, vol. 53, no. 4, pp. 279-287, 2001.

[136] M. R. Verneris, M. Karami, J. Baker, A. Jayaswal, and R. S. Negrin, "Role of NKG2D signaling in the cytotoxicity of activated and expanded CD8 ${ }^{+}$T cells," Blood, vol. 103, no. 8, pp. 3065-3072, 2004.

[137] V. Groh, R. Rhinehart, J. Randolph-Habecker, M. S. Topp, S. R. Riddell, and T. Spies, "Costimulation of CD8alphabeta T cells by NKG2D via engagement by MIC induced on virus-infected cells," Nature Immunology, vol. 2, no. 3, pp. 255-260, 2001.

[138] G. Chitadze, M. Lettau, J. Bhat et al., "Shedding of endogenous MHC class I-related chain molecules A and B from different human tumor entities: heterogeneous involvement of the "a disintegrin and metalloproteases" 10 and 17," International Journal of Cancer, vol. 133, no. 7, pp. 1557-1566, 2013. 
[139] Z. Deng, Z. Cheng, X. Xiang et al., "Tumor cell cross talk with tumor-associated leukocytes leads to induction of tumor exosomal fibronectin and promotes tumor progression," The American Journal of Pathology, vol. 180, no. 1, pp. 390-398, 2012.

[140] J. Jarczak, E. M. Kościuczuk, P. Lisowski et al., "Defensins: natural component of human innate immunity," Human Immunology, vol. 74, no. 9, pp. 1069-1079, 2013.

[141] V. S. De Paula, N. S. F. Gomes, L. G. Lima et al., "Structural basis for the interaction of human beta-defensin 6 and its putative chemokine receptor CCR2 and breast cancer microvesicles," Journal of Molecular Biology, vol. 425, no. 22, pp. 4479-4495, 2013.

[142] F. M. Vega and A. J. Ridley, "Rho GTPases in cancer cell biology," FEBS Letters, vol. 582, no. 14, pp. 2093-2101, 2008.

[143] S. P. Fortin Ensign, I. T. Mathews, M. H. Symons, M. E. Berens, and N. L. Tran, "Implications of Rho GTPase signaling in glioma cell invasion and tumor progression," Frontiers in Oncology, vol. 3, article 241, 2013.

[144] S. Schlienger, S. Campbell, and A. Claing, "ARF1 regulates the Rho/MLC pathway to control EGF-dependent breast cancer cell invasion," Molecular Biology of the Cell, vol. 25, no. 1, pp. 17-29, 2014.

[145] D. L. Crowe and C. F. Shuler, "Regulation of tumor cell invasion by extracellular matrix," Histology and Histopathology, vol. 14, no. 2, pp. 665-671, 1999.

[146] J. Westermarck and V.-M. Kähäri, "Regulation of matrix metalloproteinase expression in tumor invasion," The FASEB Journal, vol. 13, no. 8, pp. 781-792, 1999.

[147] L. G. Lima, A. C. Leal, G. Vargas, I. Porto-Carreiro, and R. Q. Monteiro, "Intercellular transfer of tissue factor via the uptake of tumor-derived microvesicles," Thrombosis Research, vol. 132, no. 4, pp. 450-456, 2013.

[148] A. M. Gil-Bernabé, S. Lucotti, and R. J. Muschel, "Coagulation and metastasis: what does the experimental literature tell us?" British Journal of Haematology, vol. 162, no. 4, pp. 433-441, 2013.

[149] G. Bendas and L. Borsig, "Cancer cell adhesion and metastasis: selectins, integrins, and the inhibitory potential of heparins," International Journal of Cell Biology, vol. 2012, Article ID 676731, 10 pages, 2012.

[150] M. Z. Wojtukiewicz, D. G. Tang, K. K. Nelson, D. A. Walz, C. A. Diglio, and K. V. Honn, "Thrombin enhances tumor cell adhesive and metastatic properties via increased alpha IIb beta 3 expression on the cell surface," Thrombosis Research, vol. 68, no. 3, pp. 233-245, 1992.

[151] O. Galindo-Hernandez, C. Gonzales-Vazquez, P. CortesReynosa et al., "Extracellular vesicles from women with breast cancer promote an epithelial-mesenchymal transition-like process in mammary epithelial cells MCF10A," Tumor Biology, pp. 1-11, 2015.

[152] M. L. Alpaugh, J. S. Tomlinson, Z.-M. Shao, and S. H. Barsky, "A novel human xenograft model of inflammatory breast cancer," Cancer Research, vol. 59, no. 20, pp. 5079-5084, 1999.

[153] N. Dhani, A. Fyles, D. Hedley, and M. Milosevic, "The clinical significance of hypoxia in human cancers," Seminars in Nuclear Medicine, vol. 45, no. 2, pp. 110-121, 2015.

[154] Y. Kato, S. Ozawa, C. Miyamoto et al., "Acidic extracellular microenvironment and cancer," Cancer Cell International, vol. 13, article 89, 2013.

[155] C. Federici, F. Petrucci, S. Caimi et al., "Exosome release and low $\mathrm{pH}$ belong to a framework of resistance of human melanoma cells to cisplatin," PLoS ONE, vol. 9, no. 2, Article ID e88193, 2014.
[156] B. Y. Wang, J. Zhang, J. L. Wang et al., "Intermittent high dose proton pump inhibitor enhances the antitumor effects of chemotherapy in metastatic breast cancer," Journal of Experimental \& Clinical Cancer Research, vol. 34, no. 1, article 85, 2015.

[157] A. Papi, S. De Carolis, S. Bertoni et al., "PPARgamma and RXR ligands disrupt the inflammatory cross-talk in the hypoxic breast cancer stem cells niche," Journal of Cellular Physiology, vol. 229, no. 11, pp. 1595-1606, 2014.

[158] Z. J. Yang, C. E. Chee, S. Huang, and F. A. Sinicrope, "The role of autophagy in cancer: therapeutic implications," Molecular Cancer Therapeutics, vol. 10, no. 9, pp. 1533-1541, 2011.

[159] D. Glick, S. Barth, and K. F. Macleod, "Autophagy: cellular and molecular mechanisms," Journal of Pathology, vol. 221, no. 1, pp. 3-12, 2010.

[160] J. A. Cho, H. Park, E. H. Lim, and K. W. Lee, "Exosomes from breast cancer cells can convert adipose tissue-derived mesenchymal stem cells into myofibroblast-like cells," International Journal of Oncology, vol. 40, no. 1, pp. 130-138, 2012.

[161] A. Desmoulière, C. Guyot, and G. Gabbiani, "The stroma reaction myofibroblast: a key player in the control of tumor cell behavior," International Journal of Developmental Biology, vol. 48, no. 5-6, pp. 509-517, 2004.

[162] W. Zhou, M. Y. Fong, Y. Min et al., "Cancer-secreted miR-105 destroys vascular endothelial barriers to promote metastasis," Cancer Cell, vol. 25, no. 4, pp. 501-515, 2014.

[163] P. Sekar, J. N. Bharti, J. S. Nigam, A. Sharma, and P. B. Soni, "Evaluation of p53, HoxD10, and E-cadherin status in breast cancer and correlation with histological grade and other prognostic factors," Journal of Oncology, vol. 2014, Article ID 702527, 4 pages, 2014.

[164] H. Lu, W. Ouyang, and C. Huang, "Inflammation, a key event in cancer development," Molecular Cancer Research, vol. 4, no. 4, pp. 221-233, 2006.

[165] T. M. Robinson-Smith, I. Isaacsohn, C. A. Mercer et al., "Macrophages mediate inflammation-enhanced metastasis of ovarian tumors in mice," Cancer Research, vol. 67, no. 12, pp. 5708-5716, 2007. 

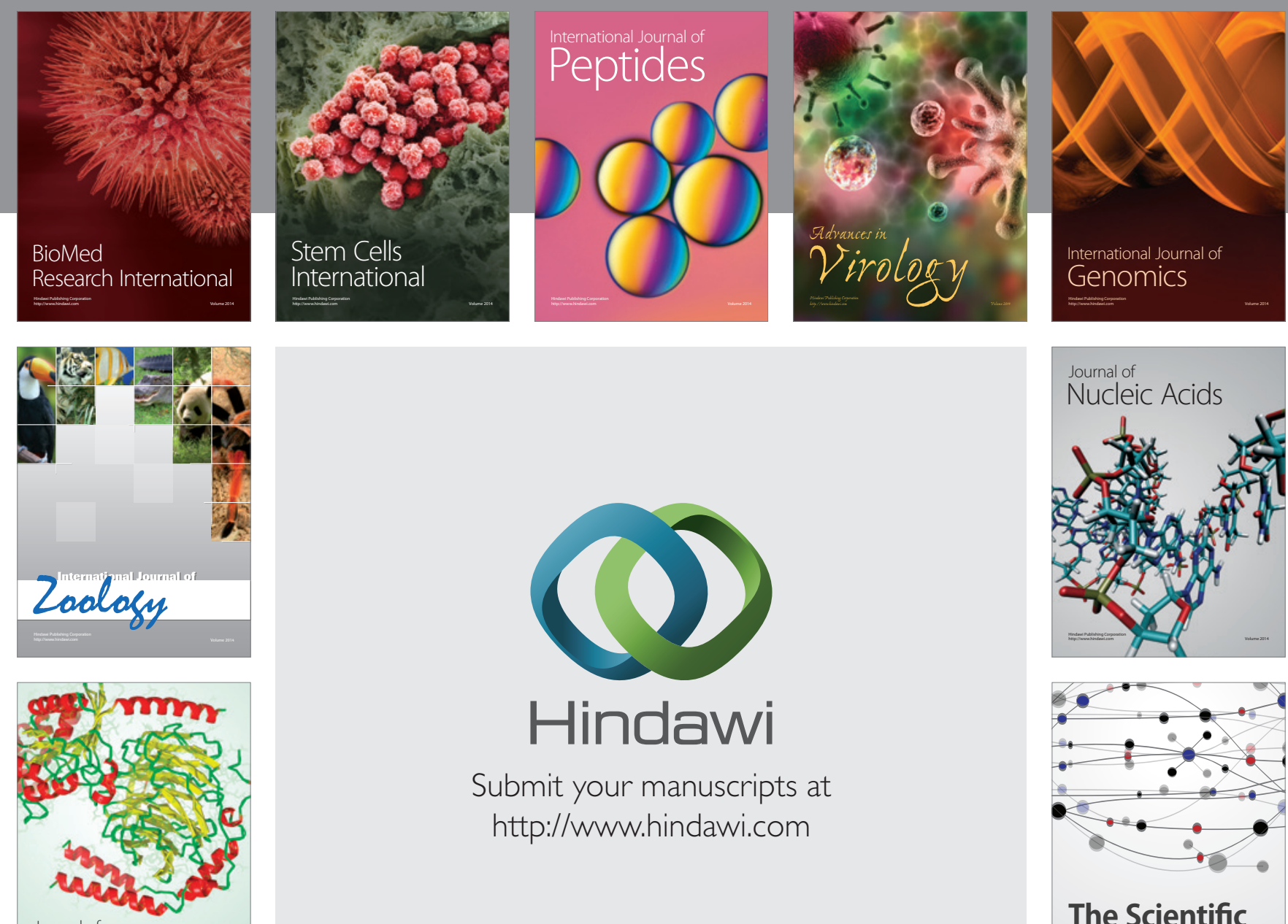

Submit your manuscripts at

http://www.hindawi.com

Journal of
Signal Transduction
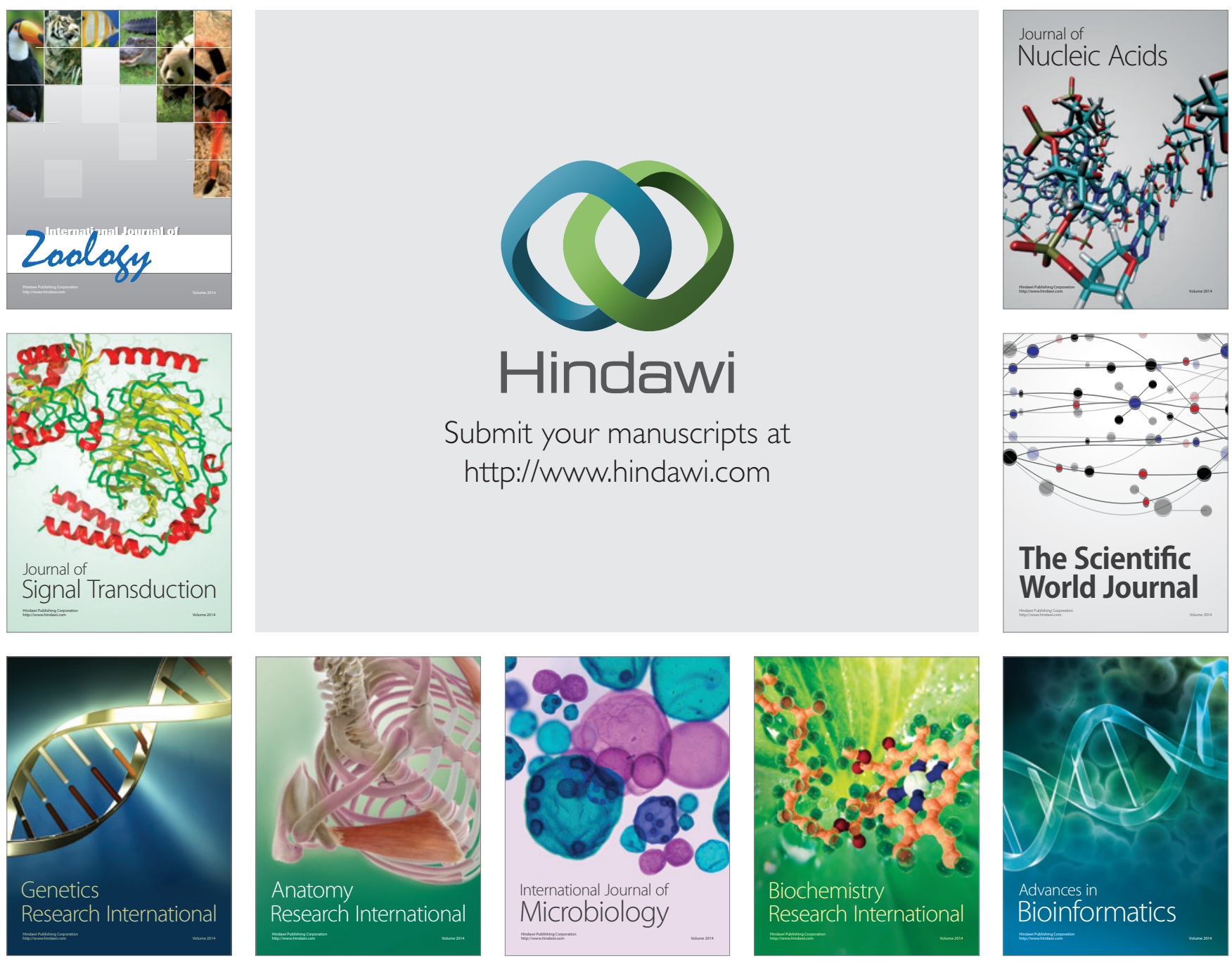

The Scientific World Journal
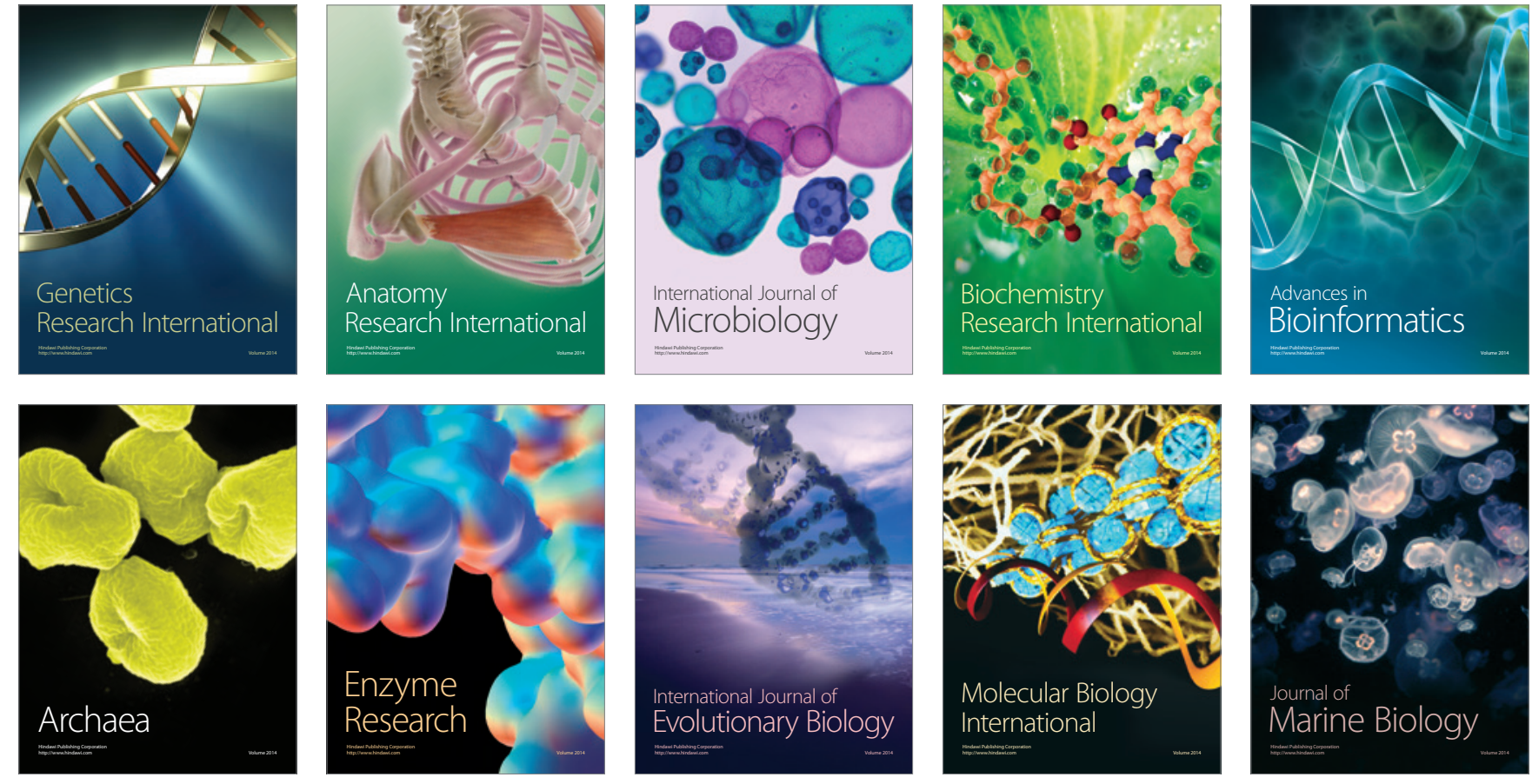